\title{
A Case Off the Bell Curve: Customization of the Dialysis Prescription - A Self-Report
}

\author{
Judy Weintraub \\ Los Angeles, Calif., USA
}

\section{Key Words \\ Calcium - Dialysis protocol - Dialysate individualization . \\ Osteomalacia $\cdot$ Phosphorus · Spontaneous fractures}

\begin{abstract}
Background/Aims: In a 35+-year dialysis patient, a series of spontaneous fractures and a history of severe somatic pains of unknown origin, superimposed on a history of generally adequate laboratory values, prompted an attempt at diagnosis of the cause of the condition. The patient was on a regimen of nocturnal home hemodialysis, a 4-night, 7-hour treatment. Physicians were divided on whether the cause might be neuropathic, muscular or osteopathic. Methods: A bone biopsy was conducted to evaluate the integrity of the bones. Results: The biopsy resulted in a diagnosis of osteomalacia - severe mineral depletion of the skeletal system. This was surprising because the hematologic laboratory values did not seem to indicate this. The calcium level in the dialysate was greatly increased, which was supplemented by moderate inclusion of sodium phosphate. Conclusion: The bones strengthened over time, resulting in no further fractures, an easing of general pain, and significantly improved mobility. The results demonstrate that customization of the dialysis prescription should be readily available for hemodialysis, whether treated in-center or at home.
\end{abstract}

(c) 2013 S. Karger AG, Basel
C 2013 S. Karger AG, Basel

0253-5068/13/0364-0215\$38.00/0

\section{Introduction}

When my husband Joel and I were preparing for our upcoming trip to Israel, I assembled all the medical documentation needed. The package included a detailed history and physical examination (H\&P). When I revisit my H\&P, I am a bit amazed. This all actually happened. I do kidney dialysis for more than 38 years now and am probably more in awe of that statement than anyone who hears it. Looking at something like my H\&P only magnifies that awe. On a day-day basis, however, it is not something that is first and foremost in my mind. As a friend and mentor, the late nephrologist who himself did dialysis for more than 2 decades, Dr. Peter Lundin, once said to me, 'We dialyze to live. We don't live to dialyze'.

I survived the primitive early years of dialysis, complete with the occasional ruptured coil and my blood sprayed over the ceiling of the pediatric dialysis unit. The process of blood purification was a dicey one. Fluid loss was obtained via the 'squeezing' of a clamp on the venous line. The clamp would sometimes loosen and fall to the ground. Fluid removal was a little like gambling back then

Judy Weintraub holds an MS in Education and is a writer, speaker and educator. She writes the healthy food blog, bumbleberrybreeze.com and lives in Los Angeles with her husband.

\section{KARGER}

E-Mail karger@karger.com www.karger.com/bpu
Judy Weintraub, MS Ed.

11344 Kiel Street

Los Angeles, CA 90049 (USA)

E-Mail judyweintraub@me.com 
with the stakes being how I would feel afterward. Removal of toxins was limited to small molecules. Middle molecule clearance would not be addressed until years later. Water purification levels for the dialysate were not even close to the standards of the Association for the Advancement of Medical Instrumentation of today. Inter- as well as postdialytic symptoms were severe. Cramping, low blood pressure, nausea, and headaches were commonplace. The only way for me to minimize the severe effects of the dialysis disequilibrium was to dialyze in the evenings so that I could go home afterwards, go to sleep, wake up in the morning to go to high school, to go to college and then graduate school, and to go to work, as the years went by.

When I initiated dialysis treatments as an adolescent in 1975, I strictly adhered to the dietary guidelines of the time: severely restricted protein, potassium, phosphorus and sodium, and no more than $500 \mathrm{ml}$ of liquid daily. As a lifelong lover of food, this was no easy task, but I rose to it, adamant to do whatever was in my power to safeguard my health. I followed the renal diet to the letter, even going so far as to weigh the protein I ate on a postage scale to comply with the $40 \mathrm{~g}$ of protein a day limit. Fruits and vegetables were severely cut back. I took it on as a challenge, very serious about not doing anything to endanger myself. Eventually, by studying the laboratory results, I came to the realization that I could reintroduce beloved fruits and vegetables into my diet without ill effect. If a cup of tomatoes was considered off limits as a high potassium food, for example, then a quarter cup would be equivalent to a low potassium selection. I realized that the dietitian walking around the dialysis unit uttering punitive dicta to people was not effective. Adult men and women hearing 'No, No, No', was not very productive.

The calcium-phosphorus balance has always been an essential part of management. The phosphate binder used in the late 70s and early 80 s was aluminum hydroxide gel (Amphogel), which led to severe aluminum toxicity in my body after 7 years. A bone biopsy followed, leading to my participation in the deferoxamine (Desferal) study led by Dr. Jack Coburn at UCLA. Thankfully, it removed the aluminum from my system and fully addressed the bone pain without undue side effects.

After the aluminum adventure, I was switched to calcium carbonate, which I took in addition to the Rocaltrol (calcitriol) that I had been taking since its appearance on the scene in 1978. Most doctors prescribe an equal amount of phosphate binders with each meal. During my graduate school and work years, I ate a very small breakfast and did not use binders with that meal, with no rise in phos-
Table 1. Laboratory values

\begin{tabular}{lcll}
\hline Date & $\begin{array}{l}\mathrm{Ca}, \\
\mathrm{mg} / \mathrm{dl}\end{array}$ & $\begin{array}{l}\mathrm{PO}_{4}, \\
\mathrm{mg} / \mathrm{dl}\end{array}$ & $\begin{array}{l}\text { Vitamin D, } \\
\mathrm{pg} / \mathrm{dl} \\
{\left[1,25(\mathrm{OH})_{2} \mathrm{D}_{3}\right]}\end{array}$ \\
\hline May 7, 2010 & 8.3 & 2.8 & \\
September 6, 2010 & 8.6 & 2.2 & \\
April 4, 2011 & 8.0 & 2.2 & 27 \\
October 1, 2011 & 6.9 & 5.2 & \\
December 24, 2011 & 6.5 & 3.7 & \\
January 28, 2012 & 7.8 & 6.2 & \\
April 13, 2012 & 10.4 & 3.3 & 51 \\
August 6, 2012 & 9.5 & 2.9 & - \\
October 4, 2012 & 9.8 & 2.7 & 62 \\
January 7, 2013 & 9.5 & 3.3 & \\
August 13, 2013 & 9.1 & 3.8 & \\
\hline Reference range & $8.6-10.2$ & $2.5-5.0$ & $31-100$ \\
\hline
\end{tabular}

phorus level. My thinking was that if calcium binds with phosphorus, should not the amount of calcium taken be in proportion to the amount of phosphorus-laden food eaten? I recently heard of research suggesting just that.

My calcium and phosphorus levels were historically under control. Phosphorus levels over the years ranged from 3 to 4 and calcium levels between 9 and 10. Fast forward to my body after decades of dialysis. My body recognizes the 'normal' cells in the membranes that line renal capillaries as abnormal. It therefore produces a destructive immune response to those 'normal' cells, which causes damage to transplanted kidney tissue. This was only revealed after my third attempt at transplantation. Dialysis is thus the renal replacement therapy for me. This included 15 years of stable in-center hemodialysis, 12 years of highly successful continuous ambulatory peritoneal dialysis, and eventually $11+$ years of nocturnal home hemodialysis (including 4 great years of extended therapy with NxStage System One).

However, all the close attention to nutrition, exercise and proactive management of my care could not fully do away with the reality of living without kidney function for decades. The house I live in was showing signs of wear and tear. The accumulation of amyloid was creating new challenges. Neuropathy began and worsened over time. I experienced pain in my extremities. Was it the muscles, nerves or fascia?

Spontaneous stress fractures began occurring with disturbing regularity. A broken toe, a fractured rib, a fractured metacarpal and then... a broken right femoral neck. The pain was excruciating as the paramedics lifted me in a chair down the stairs. Less than 6 months later, follow- 


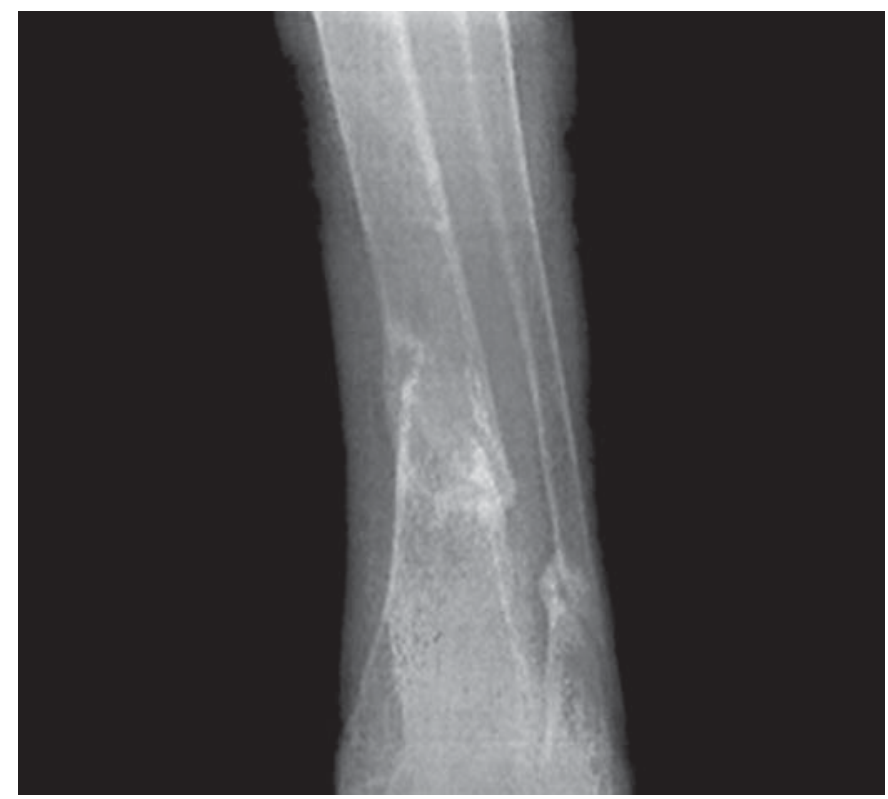

Fig. 1. X-ray on October 27, 2011.

ing hip surgery, a nagging pain in the center of my left shin would not subside as I struggled to walk again. I was told it could be nerve pain, or muscle pain, or neither. A simple X-ray revealed a fracture in the left tibia.

Support in a boot for the next month did not help; further displacement had occurred. X-rays revealed both a fractured left tibia and fibula. Monthly trips to the orthopedic clinic ensued. The cast was changed regularly and $\mathrm{X}$-rays showed no signs of healing. A trauma surgeon wanted to insert a pin, stating only a 50/50 chance of success. 'That's a coin flip', I said. He shrugged. 'You have no other choice'. My nephrologist was horrified. If it did not work, I could be worse off.

I did have a choice, and I chose the counsel of some of the doctors who I trusted and admired most, in addition to my retired and current nephrologists.

My email search, borne from speaking around the country for more than 1 decade and developing connections with physicians who I respected, led me from Tom Golper, Robert Lockridge and Christopher Blagg to Stuart Sprague, Frederick Singer and finally to Isidro Salusky, who practices pediatric nephrology with a specialty in bone disease in my own backyard at UCLA. A dialogue amongst these excellent physicians ensued, which by no means led to consensus, but indicated that a bone biopsy was the prudent way to go. By that time, simply getting me on the table was a painful ordeal.

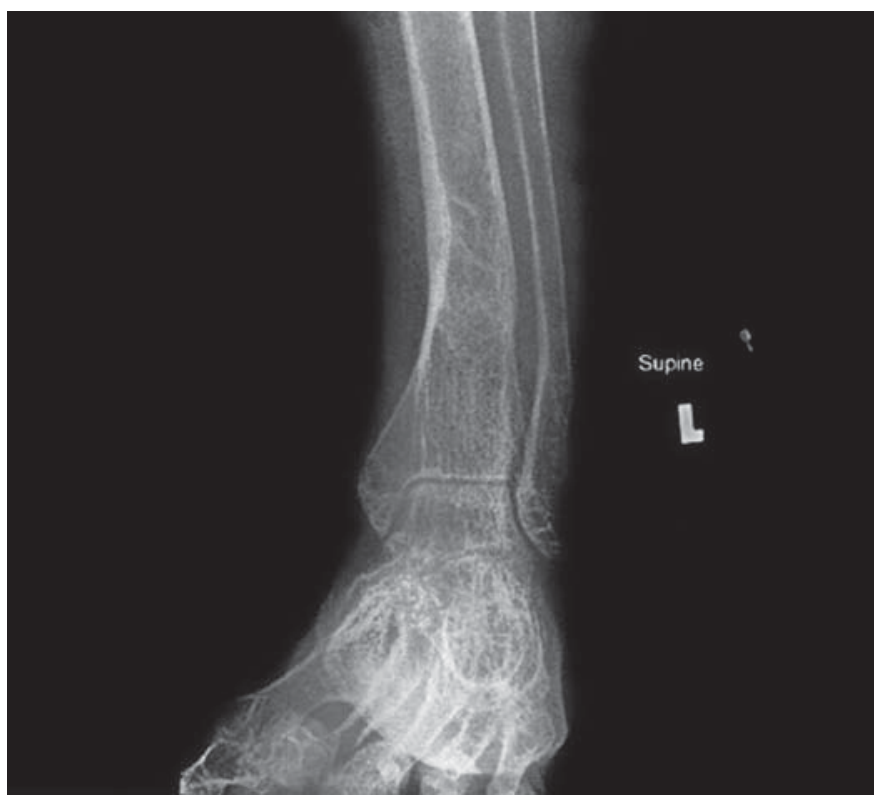

Fig. 2. X-ray on May 23, 2013.

The bone biopsy resulted in a diagnosis of severe osteomalacia. All that undiagnosed pain was coming from the bones themselves. I was told that of all the possible etiologies, severe depletion of calcium and phosphorus was one that was treatable. The course of action suddenly seemed so simple. It was a revelation.

Vitamin $\mathrm{D}_{2}$ was added to my medication, the dosage of calcitriol was increased, and more importantly, the dialysate prescription itself was changed. The amount of calcium was increased from 2.5 to 4.0 (it was slowly decreased over time to 3.0) and sodium phosphate was added to the dialysate. (I was clearing the shelves of Fleet Enema from my local pharmacy. God knows what the cashier was thinking.)

The ordeal of having two broken bones in my leg for 1.5 years (and the accompanying muscle atrophy) was finally coming to a close. After all that time in a wheelchair, I slowly transitioned to bearing weight again.

Given what I experienced, I had to ask myself a humbling question: Is there a possibility of too much dialysis? Several fine physicians have said to me, 'There is no such thing as too much dialysis'. That may be true, but in my opinion, only in tandem with customization of the dialysate, if needed. In my case, that meant the addition of both calcium and phosphorus.

Today, I walk a fine line between too much and not enough supplementation. As I watched calcifications ap- 
pearing on my body, I realized the need, after 2 years, for a follow-up bone biopsy. The results corroborated that my bones were once again strong, something I already knew from my absence of pain, significantly increased range of motion and stamina, and my returned mobility.

Many doctors stick to a uniform protocol with all their patients. On the one hand, that is, of course, a means to offer adequate care for all. But my nephrologist took the time and we went completely outside the typical dialysis protocol. What would have happened if we had agreed with the surgeon wanting to operate on my leg and had not done the bone biopsy? Not only might the operation not have helped, but also the results could have made the situation far worse. We shudder to think.

Do not misconstrue my remarks as an argument that there is such a thing as too much dialysis - nocturnal treatments do more for me than any other therapy can provide. My urea clearance is outstanding and albumin levels are normal. I eat very healthy and mostly unrestricted, albeit with a watchful eye on sodium and fluid. I dialyze at home 4 nights a week (7-hour treatments) and sometimes make changes to my schedule according to my activities. As has been well documented in the literature, to vary the dialysis time strategy per patient per week is a most appropriate customization of care. I no longer get sick during or after treatments because I run very gently, something I could not do with in-center dialysis. All in all, the treatment is highly physiologic.

What I needed, however, in doing dialysis over the long term is different from what most people need. After all, how many people need phosphorus, of all things, add$e d$ to their dialysate bath? Ultimately, monitoring blood purification was not sufficient. Laboratory values do not necessarily reflect exactly what is going on in the body. While my blood chemistries reflected levels of calcium and phosphorus that were normal or below normal, my bones were being depleted of these minerals. We needed to broaden the scope, pull back and investigate the larger picture. For me that meant undergoing the pivotal bone biopsy. I had been traumatized from the earlier one I had 30 years before and it took a lot for me to get on board with this course of action. If not for that biopsy, however, we would have continued flying blind.

This is an e-mail I recently received from my current nephrologist, Dr. Larry Froch:
Dear Judy, I looked at your films and am very pleased to see progress. I don't have to tell you that your case is an interesting one. Since we have a very well defined clinical course, serial images before and during treatment, an abundance of lab data pretreatment and pre and post dialysate modification and a bone biopsy that played $a$ critical role in your management-I am going to write up your case and submit for publication. I certainly learned a lot from you and every nephrologist I have presented your case to has zero experience with this and no clue how to manage. It's time for there to be a refresher course in the medical literature.

How far have we really come? As I was working on this piece, my husband and I took a 3-day trip to Santa Fe, N.Mex., USA. I arranged to do 1 dialysis treatment in a clinic there. The clinic is owned by one of the three top dialysis providers in this country and I was told that the center was brand new with state-of-the-art equipment. I had all of my information sent, which included my treatment prescription stating my use of a 3.0 Ca dialysate solution. Once my treatment was initiated at the clinic, I ran through a mental checklist with the nurse. 'And I'm on a 3.0 Ca, right?' The nurse looked at me and hesitated, 'No, you're on a $2.5 \mathrm{Ca}$ dialysate solution. The dialysate is mixed in a central system and it goes to all the machines. I wouldn't know how to give you more calcium'. I looked at her, somewhat in disbelief. 'I didn't even know you could change it', she said.

In an effort to deliver a standardized service that meets certain basic criteria, something is being lost. Let us say $90 \%$ of patients may be receiving dialysis care that sufficiently addresses their needs, but for the other $10 \%$ or so, it is most definitely not the optimal dialysis prescription for them. Should this group not have the right to optimal care even if it means an individualized prescription? In fact, standard dialysate is appropriate only when customization is readily available, and not just for highly unusual patients, but for all patients who may benefit from it (and there will be many - especially in cases of potassium optimization).

If I had settled for current protocol, I may not have been here to convey these thoughts to you. I urge you to consider this as you develop care plans for your patients and reevaluate options as circumstances change for them over the years. By individualizing dialysis therapies, you just may be partnering with them to help your patients attain a higher quality of life. 